(6) OPEN ACCESS

\title{
Safety in healthcare is a moving target
}

\section{Charles Vincent, ${ }^{1}$ Rene Amalberti ${ }^{2}$}

${ }^{1}$ Department of Experimental Psychology, University of Oxford, Oxford, UK

${ }^{2}$ Haute Autorité de Santé, Paris, France

\section{Correspondence to}

Professor Charles Vincent, Department of Experimental Psychology, University of Oxford, Tinbergen Building, 9 South Parks Road, Oxford OX1 3UD, UK; charles.vincent@psy.ox.ac.uk

Received 16 May 2015 Accepted 18 May 2015 Published Online First 6 July 2015

\section{CLLinked}

- http://dx.doi.org/10.1136/ bmjqs-2014-003702

- http://dx.doi.org/10.1136/ bmjqs-2015-004461

\section{CrossMark}

To cite: Vincent $C$, Amalberti R. BMJ Qual Saf 2015;24:539-540.
Safety in healthcare is a constantly moving target. As standards improve and concern for safety grows, we come to regard an increasing number of events as patient safety issues. In this respect, healthcare differs from almost all other safety-critical industries. What we regard as harm in, for instance, civil aviation remains the same whatever advances may occur in aviation technology or practice. In contrast, innovation and improving standards in healthcare alter our conceptions of both harm and preventability.

In the 1950s, many complications of healthcare were recognised, at least by some, but largely viewed as the inevitable consequences of medical intervention. ${ }^{1}$ Over time, certain types of incidents come to be seen as both unacceptable and potentially preventable. The clearest example in recent times is healthcare-associated infections, which in the 1980s were still regarded as unfortunate, but inevitable. With increased understanding of underlying processes, mechanisms of transmission and methods of prevention, coupled with major public and regulatory pressure, such infections are now seen as patient safety issues. ${ }^{2}$ The list of 'never events' put forward in various countries, such as wrong-site surgery, is similarly an assertion that certain types of failure cannot be tolerated. ${ }^{3}$

In the last 10 years, as more types of harm have come to be regarded as preventable, the perimeter of patient safety has expanded. We could now include pressure ulcers, falls, venous thromboembolism and catheters with associated urinary tract infections, which, if not entirely preventable, can at least be substantially reduced. $^{4}{ }^{5}$ In the UK, the Francis Report into Mid Staffordshire Hospitals NHS Trust highlighted additional risks to patients, such as malnutrition, dehydration and delirium, all of which are now being viewed as safety issues. ${ }^{67}$ We might also consider adverse drug events in the community that cause admission to hospital, polypharmacy and general harm from overtreatment. ${ }^{8}$ All these, in the past, might have been regretted, but now receive greater attention by being viewed under the safety umbrella.

The perimeter of safety is, therefore, expanding. This is welcome for patients as it reflects rising standards and aspirations. However, the shifting perimeter does present problems, both conceptual and practical. The definition of harm seems increasingly difficult to pin down as more and more events are badged as safety issues. This raises the questions of whether we need to reconsider the measurement of adverse events.

An adverse event is defined as an unintended injury caused by healthcare management rather than the patient's disease, and which results in a longer hospital stay, temporary or permanent disability or death. This concept was 'good enough' for the purposes of the major record reviews in that these studies showed that the risks of healthcare to patients were considerably larger than it had previously been realised. ${ }^{9} 10$ Tracking changes in adverse events over time, however, has been considerably more difficult, with many studies showing little or no change over many years. ${ }^{11} 12$

The impressive study by Baines $e t a l^{13}$ has demonstrated reductions in adverse events concurrent with major patient safety programmes in the Netherlands. The paper reports what amounts to three major national adverse-event studies over time. The authors previously reported the comparison between the first two periods, showing an increase in overall adverse events from $4.1 \%$ in 2004 to $6.2 \%$ in 2008 , possibly due to better documentaion. ${ }^{14}$ Reassuringly, the rate of preventable adverse events did not change significantly $(1.8 \%$ in 2004 vs $1.6 \%$ in 2008). In contrast, the most recent report shows no change in the rate 
of adverse events between 2008 and 2012, but a marked reduction (45\%) in preventable adverse events. After adjusting for oversampling of deceased patients and patient characteristics, the decrease in preventable adverse event rate between 2008 and 2012 was still noteworthy (30\%), but not quite statistically significant $(p=0.10$ after adjustment).

The authors rightly discuss a number of potential interpretations of the data, but argue convincingly that the national drive to improve safety is one important factor in the reduction in preventable adverse events. They also allude briefly to the problems of maintaining similar definitions over long time periods, which is a critical issue, since, if the perimeter of safety is expanding, it becomes more difficult to demonstrate improvement over time. Judgements of what was considered an adverse event and what was preventable in 2012, at the time of their third major record review, may well be rather different from those in 2004, at the time of their first review. ${ }^{15}$ Rising standards of care will actually make it harder to demonstrate long-term reduction in the overall rate of adverse events, which, if correct, make the findings of the recent Dutch study still more impressive. This does not mean we should abandon the term 'adverse event', still less abandon attempts to improve safety, but we do need to recognise its limitations.

The term 'adverse event' has some parallels with the term 'disease'. Imagine that one became aware that disease was prevalent, but did not yet have good classification systems. It would make sense to do an initial survey of disease generally, and make some rough assessment of the overall scale of the problem; this was essentially the approach of the major record-review studies of adverse events that launched the field of patient safety. Asking 'has the disease burden reduced' is a reasonable question, but, in practice, one would define and track specific diseases, which would imply that we also need to begin to separate out specific types of adverse events. Future large-scale studies should attempt to specify in advance at least a large proportion of specific types of adverse events, which should enable more precise tracking both of specific types of harm and of the overall level of adverse events. ${ }^{16}$ This will never be a complete solution as there will always be problems that are rare or elude precise definition, and which will require a generic 'other' category.

In the longer term, we need to set measures of harm alongside measures of the beneficial effects of healthcare, first at the level of populations and then, more ambitiously, for individual patients. Ultimately, the aspiration should be to mirror our experience as patients and be able to reflect for any one individual the overall balance of benefits and harms of healthcare and the accompanying experience for patients and families.
Funding Health Foundation.

Competing interests None declared.

Provenance and peer review Not commissioned; internally peer reviewed.

Open Access This is an Open Access article distributed in accordance with the Creative Commons Attribution Non Commercial (CC BY-NC 4.0) license, which permits others to distribute, remix, adapt, build upon this work noncommercially, and license their derivative works on different terms, provided the original work is properly cited and the use is non-commercial. See: http://creativecommons.org/licenses/by$\mathrm{nc} / 4.0$ /

\section{REFERENCES}

1 Sharpe VA, Faden AI. Medical harm. Historical, conceptual and ethical dimensions of iatrogenic illness. Cambridge: Cambridge University Press, 1998.

2 Burke JP. Infection control-a problem for patient safety. N Engl J Med 2003;348:651-6.

3 Milstein A. Ending extra payment for "never events"-stronger incentives for patients' safety. $N$ Engl J Med 2009;360:2388-90.

4 Sullivan N, Schoelles KM. Preventing in-facility pressure ulcers as a patient safety strategy: a systematic review. Ann Int Med 2013;158(5_Part_2):410-16.

5 Chopra V, Anand S, Hickner A, et al. Risk of venous thromboembolism associated with peripherally inserted central catheters: a systematic review and meta-analysis. Lancet 2013;382:311-25.

6 Francis R. Independent inquiry into care provided by Mid Staffordshire NHS Foundation Trust January 2005-March 2009. London: Department of Health, 2013.

7 Long SJ, Brown KF, Ames D, et al. What is known about adverse events in older medical hospital inpatients? A systematic review of the literature. Int J Qual Health Care 2013;25:542-54.

8 Gandhi TK, Weingart SN, Borus J, et al. Adverse drug events in ambulatory care. N Engl J Med 2003;348:1556-64.

9 Woloshynowych M, Neale G, Vincent C. Case record review of adverse events: a new approach. Qual Saf Health Care 2003;12:411-15.

10 de Vries EN, Ramrattan MA, Smorenburg SM, et al. The incidence and nature of in-hospital adverse events: a systematic review. Qual Saf Health Care 2008;17:216-23.

11 Vincent C, Aylin P, Franklin BD, et al. Is health care getting safer? BMJ 2008;337:a2426.

12 Landrigan CP, Parry GJ, Bones CB, et al. Temporal trends in rates of patient harm resulting from medical care. $\mathrm{N} \mathrm{Engl} \mathrm{J}$ Med 2010;363:2124-34.

13 Baines R, et al. How effective are patient safety initiatives? A retrospective patient record review study of changes to patient safety over time. BMJ Qual Saf 2015;24:561-71.

14 Baines RJ, Langelaan M, de Bruijne MC, et al. Changes in adverse event rates in hospitals over time: a longitudinal retrospective patient record review study. BMJ Qual Saf 2013;22:290-8.

15 Amalberti R, Benhamou D, Auroy Y, et al. Adverse events in medicine: easy to count, complicated to understand, and complex to prevent. J Biomed Inform 2011;44:390-4.

16 Wong BM, Dyal S, Etchells EE, et al. Application of a trigger tool in near real time to inform quality improvement activities: a prospective study in a general medicine ward. BMJ Qual Saf 2015;24:272-81. 